\title{
Empresas Multinacionars e Soberania do Estado
}

\author{
Dalmo de Abreu Dallari \\ Professor Titular de Teoria Geral do Estado da \\ Faculdade de Direito da USP

\begin{abstract}
Sumário: I - Importância e Atualidade do Tema; II - Pontos de Interesse e Controvérsia; III - A Soberania; IV - As Empresas Multinacionais: 1. O Problema da Conceituação 2. Constituição - 3. Classificação - 4. O Problema da Nacionalidade; V - As Multinacionais e as Leis Nacionais; VI - As Multinacionais $e$ os Interesses Nacionais; VII - $O$ Relacionamento das Multinacionais com a Soberania do Estado.
\end{abstract}

\section{Importância e atualidade do tema}

O relacionamento entre as empresas multinacionais e a soberania do Estado é assunto de suma importância e da maior atualidade, que já vem sendo enfrentado por estudiosos de várias especialidades e que se vem constituindo num desafio, sobretudo para os juristas.

Relativamente à soberania, desde logo se sabe que é um conceito fundamental, debatido há vários séculos e, apesar disso, ainda altamente polêmico. Para alguns a soberania é a base daquilo que denominam "o egoísmo dos Estados", e por isso a condenam. Para outros a soberania, ao contrário disso, é, precisamente, a base que assegura a igualdade jurídica de todos os Estados, e por isso a louvam. Dois eminentes internacionalistas, KAPLAN e KATZENBACH, num excelente trabalho em que estudam os fundamentos políticos do Direito Internacional, mencionam a soberania como um dos temas mais difíceis do Direito, por considerá-lo equívoco e, além disso, pela constatação de que a soberania se tornou um símbolo altamente emocional. PAULO BONAVIDEs chama a atenção para esse aspecto quando diz, de maneira muito expressiva, que "o nacionalismo prestigia a soberania". E, na verdade, basta ressaltar esse aspecto para se compreender, ou para se sentir, a conotação realmente emocional que envolve o tema "soberania" 
"Empresas multinacionais" é um tema que, para o Direito, pode ser considerado novo. As empresas multinacionais, de um modo geral, são a expressão de um novo poder, que decorre da internacionalização das atividades econômicas. E curiosamente, embora se esteja no plano das atividades econômicas, geralmente orientadas por critérios mais racionais, quanto às empresas multinacionais se verifica também uma reação emocional. Há os defensores intransigentes da empresa multinacional e há aqueles que a condenam de maneira absoluta.

Em face desses aspectos relacionados com a soberania e com as empresas multinacionais várias perguntas se põem: em primeiro lugar, é possível a convivência da soberania do Estado com a empresa multinacional? Se afirmativa a resposta a essa primeira indagação, evidentemente será necessário indagar em que termos será possível essa convivência. Mas, além disso, um aspecto mais específico do âmbito jurídico é a indagação a respeito de qual tem sido a reação do Direito perante os conflitos entre a soberania do Estado e as empresas multinacionais. Para responder a essas indagações, que são realmente básicas, será necessário esclarecer alguns pontos fundamentais, que passam a ser considerados.

\section{Pontos de interesse e controvérsia}

Em primeiro lugar, é preciso tratar da fixação do conceito jurídico de soberania e de sua significação. Asssinale-se desde logo que, em relação à soberania, é tão vasta a bibliografia, tanta coisa se tem dito e estudado, que, não obstante ainda se mantenha um aspecto polêmico, seria desnecessário e inoportuno, em face do tema deste trabalho, demorar-se em demasia em sua análise. Será feita, portanto, a verificação breve de alguns aspectos fundamentais, para que se possa em seguida fazer a comparação entre a soberania do Estado e as empresas multinacionais.

Depois desse breve estudo a respeito da soberania se passará à verificação do conceito de empresa multinacional. Neste ponto, quando se penetrar no âmbito do estudo da empresa multinacional, aí sim, será necessário aprofundar mais, tanto pela circunstância de que se trata de um tema relativamente novo, quanto porque através do conhecimento mais preciso, o quanto possível preciso, de aspectos jurídicos relacionados com a empresa multinacional é que será possível responder às indagações formuladas de início. 
Após ter verificado o conceito de empresa multinacional se passará ao exame de alguns problemas jurídicos da maior relevância, suscitados pela existência da empresa multinacional, a começar por considerações relativas à sua própria constituição. Em seguida, serão abordados problemas relacionados com a sua nacionalidade e depois se examinará o comportamento dessas empresas perante as leis nacionais. Isto levará, necessariamente, à consideração de um dos aspectos mais controvertidos, que é precisamente a verificação da possibilidade de controle das multinacionais pelos Estados. Prosseguindo, será analisado o comportamento das empresas multinacionais perante os interesses nacionais e depois disso se poderá concluir, fazendo o relacionamento da soberania do Estado com as empresas multinacionais.

\section{A Soberania}

De acordo com o plano estabelecido, deve-se iniciar com algumas considerações fundamentais a respeito da soberania. Como se sabe o conceito de soberania só aparece no século XVII e é afirmado para harmonizar e hierarquizar poderes sociais, num momento em que uma multiplicidade e uma multiplicação de núcleos de poder e num momento em que muitos desses núcleos pretendem concorrer com o próprio poder do Estado. Daí então a absoluta necessidade da hierarquização.

E quando se faz a afirmação do conceito de soberania, encontrando-se nessa afirmação a presença das circunstâncias históricas que levaram a ela, a soberania é concebida como um poder "absoluto e perpétuo", passando depois a ser conceituada como "um poder incontrastável", ou seja, é um poder que não admite concorrentes. A soberania afirmada dessa maneira, como poder incontrastável, possibilitou muitos excessos, que levaram justamente àquela afirmação de que a soberania é a base do egoísmo dos Estados.

Entretanto, com o avanço do Direito no terreno político, e por influência do Direito, a soberania também foi sendo disciplinada, foi ganhando uma significação jurídica e passou a ser considerada, segundo um conceito técnico-jurídico, como "o poder de decidir em última instância sobre a eficácia das normas jurídicas". E, pois, o poder de decisão em última instância sobre a eficácia das normas jurídicas, significando isso que qualquer norma que pretenda atuar no âmbito do Estado fica sujeita à apreciação de sua eficácia pelo poder soberano, quer sejam normas oriundas de outras soberanias ou normas oriun- 
das de grupos inferiores, públicos ou privados. Assim, portanto, em qualquer hipótese a soberania do Estado deve prevalecer.

A efetividade desse poder soberano foi obtida graças a um complemento, que foi a delimitação espacial, ou seja, a fixação do conceito de território. E exatamente pela verificação de que esses conceitos se completam e, no seu entender, pela constatação de que eles definem praticamente o Estado, foi que SANTI Romano concluiu que o Estado pode ser definido como "ordem jurídica territorial e soberana", porque, a seu ver, aí estão os dados fundamentais.

Relativamente à significação da soberania, é valioso o ensinamento do professor PAULO BONAVIDES, que em várias oportunidades tratou do tema e o expôs com muita objetividade e precisão. Assinala PAULo Bonavides a existência de uma dupla significação: uma significação "interna", que é a soberania como "expressão de um poder de império que tem o Estado sobre o território e sobre a população, bem como a superioridade do poder político frente aos demais poderes sociais, que lhe ficam sujeitos, de forma mediata e imediata". Essa é, portanto, a significação interna, da maior relevância, que será muito importante, imediatamente importante, no confronto da soberania com as empresas multinacionais. Além dessa significação interna há uma significação "externa", que é "a manifestação independente do Estado perante outros Estados". Em outras palavras, é a afirmação de que a ordem jurídica do Estado não se submete a qualquer outra ordem jurídica. O Estado reconhece nos demais Estados seus iguais, porquanto são igualmente soberanos. Não os admite, entretanto, como superiores. E a conseqüência disso é que dentro do território todos os poderes estão submetidos ao poder do Estado.

Em face desses aspectos básicos relacionados com a soberania, já se pode então perguntar: como enquadrar as empresas multinacionais nesse Estado soberano? Por que razão ocorrem conflitos entre a soberania do Estado e as empresas multinacionais? E como vêm sendo resolvidos esses conflitos?

\section{As Empresas Multinacionais}

\section{O problema da conceituação}

O primeiro aspecto a ser abordado é o que se refere ao conceito de empresa multinacional. O que é "empresa multinacional"? Na verdade, a resposta ainda não foi dada de maneira 
satisfatória ou que possa ser considerada definitiva. Apesar de inúmeros estudos a respeito do assunto, verifica-se que ainda existe uma procura da conceituação satisfatória. Verifica-se também que, no âmbito jurídico, é menor a quantidade de estudos dedicados ao problema da empresa multinacional.

Percebendo a importância do problema e reconhecendo a possibilidade de sua influência sobre a própria paz mundial, a Organização das Nações Unidas, por seu Conselho Econômico e Social, decidiu, em julho de 1972, compor um grupo de especialistas, para estudar aspectos básicos relacionados com a empresa multinacional, a partir da própria conceituação. Esse grupo ainda não apresentou resultados, mas, para auxiliá-lo, a Secretaria Geral da ONU promoveu uma série de estudos preliminares e em agosto de 1973 publicou um trabalho que foi intitulado Multinational Corporations in World Development, trabalho substancioso, com quase duzentas páginas, contendo quarenta e três anexos, fornecendo dados estatísticos e procedendo também a um inventário de teorias relativamente às empresas multinacionais. O Anexo II é todo dedicado aos conceitos de empresa multinacional, havendo üma coleção de mais de vinte conceitos. Dentre esses serão em seguida destacadós alguns dos mais expressivos.

Dois autores ingleses, Michael Brooke e H. LeE Remmers, assim se referem à empresa multinacional, procurando conceituá-la: "Companhia multinacional é uma empresa que realiza suas principais operações, ou fabricação ou obtenção de serviços, em pelo menos dois Estados". Outro autor, também inglês, JoHN H. DuNNING, assim a conceitua: "Empresa internacional ou multinacional é aquela que realiza ou controla a produção de bens em mais de um Estado". Finalmente, outro conceito, também bastante expressivo, é o formulado por um eminente professor de Harvard, que há vários anos vem publicando trabalhos sobre empresas multinacionais, que é RAYMOND VERNON. Para VERNoN "empresa multinacional é uma companhia matriz que controla um grande conjunto de empresas de várias nacionalidades".

Procedendo-se a uma síntese desses conceitos, o que se verifica, desde logo, é que, na realidade, a conceituação resta imprecisa. Há inúmeros pontos que são comuns, há inúmeros dados que comparecem nas várias conceituações, notando-se, porém, que há uma imprecisão inclusive quanto à denominação "multinacional". e outras que aparecem nesses e em outros conceitos, como "transnacional" ou "internacional". E o que se pode fixar como dado comum é que a empresa é multinacional 
quando opera em dois ou mais Estados, conjugando fatores de produção. Evidentemente, é ainda uma noção precária, uma noção apenas preliminar. $O$ exame de alguns aspectos jurídicos irá esclarecer melhor essa conceituação, além de revelar algumas das principais dificuldades relacionadas com a empresa multinacional.

\section{Constituição}

O primeiro ponto importante e esclarecedor é o que se relaciona com a constituição da empresa multinacional. $O$ que se verifica é que a empresa multinacional sempre se constitui, sempre se organiza, segundo alguma lei nacional. Na prática, onde se tem um grupo multinacional, que se convencionou chamar de empresa multinacional, cada componente se constitui segundo a lei do Estado em que se localiza e isso já nos revela a autonomia de cada componente do grupo e leva, necessariamente, à afirmação de uma personalidade jurídica própria de cada componente. E dessa circunstância decorrem conseqüências de extrema gravidade.

Desde logo nota-se a existência de um evidente descompasso, porquanto a própria empresa multinacional, que desde a sua constituição já se compõe, de fato, como empresa multinacional, adota a roupagem de empresa nacional. Mas além disso, e o que é mais grave, essa empresa multinacional, exatamente porque os componentes são autônomos e têm personalidade jurídica própria, vai adquirir a possibilidade de contratar consigo mesma. Essa é uma possibilidade extremamente grave, que o direito dá à empresa multinacional e que tem conseqüências muito sérias, sobre as quais mais adiante se dirá alguma coisa.

\section{Classificação}

O segundo aspecto que aparece mencionado naquele trabalho da ONU é uma classificação das empresas multinacionais, pretendendo-se que através da classificação se tenha a possibilidade de um tratamento jurídico diferenciado. $O$ que ali se encontra é uma classificação feita de acordo com a localização dos interesses fundamentais da empresa multinacional.

Dentro dessa orientação, são indicados três tipos de empresa multinacional: $10^{\circ}$ a empresa chamada "etnocêntrica", que fixa seus interesses fundamentais num determinado Estado; 
$20^{\circ}$ a empresa denominada "policêntrica", que tem interesses dispersos por vários Estados; $3^{\circ}$ uma terceira espécie, a empresa multinacional "geocêntrica", que não estabelece essa delimitação e expande seus interesses por todo o âmbito mundial. $\mathrm{Na}$ realidade, quanto a essa classificação - que ainda não foi considerada por qualquer legislação, embora seja mencionada com certa ênfase no trabalho referido - , pode-se dizer que ela será útil, sem dúvida, para orientar uma futura legislação. Por ora, exatamente porque não penetrou nas legislações, serve apenas para demonstrar, uma vez mais, a grande complexidade do problema.

\section{O Problema da Nacionalidade}

Outro ponto relacionado com as multinacionais, e também de grande importância, é o que se refere à sua nacionalidade. Qual a nacionalidade de uma empresa multinacional? Esse problema é de difícil solução e sobre ele muita coisa se tem dito, desenvolvendo-se, às vezes, uma argumentação complicada para buscar resposta a essa indagação.

$\mathrm{O}$ que se verifica é que, em termos de direito positivo, as empresas ou são "empresas nacionais" ou são "empresas estrangeiras", pois as legislações ainda não criaram o tipo "empresa multinacional". Então a empresa multinacional, ou por sua matriz ou pelas subsidiárias componentes do grupo, será julgada empresa nacional ou estrangeira, de acordo com a apreciação de cada Estado, que considere o grupo no seu todo ou considere algum dos componentes.

Pela experiência já se percebeu que a falta desse tipo especial, - empresa multinacional, que não seja nacional nem estrangeira, - já vem acarretando uma série de dificuldades, porquanto muitas vezes a empresa, que nasceu multinacional e é multinacional, vale-se do fato de que não existe nas legislações a possibilidade desse enquadramento e procura impor-se como empresa nacional, porquanto muitos benefícios lhe advêm disso. E a inexistência de critério mais claro para fixação da nacionalidade, a inexistência, sobretudo, do tipo "empresa multinacional", torna praticamente impossível aos Estados uma definição mais precisa dessa nacionalidade. Como se sabe, inúmeros critérios vêm sendo tentados e adotados para alcançar uma definição melhor da nacionalidade das empresas.

E muito importante e oportuno examinar o que vem ocorrendo no Estado brasileiro. 
E tradicional no Brasil o critério segundo o qual a forma de organização e o local da sede é que definem a nacionalidade da empresa. Entretanto, a legislação brasileira sobre o mercado de capitais, surgida em 1965, introduziu uma inovação, quando, para certos efeitos, equiparou a empresas estrangeiras aquelas que tiverem sede no Brasil mas que sejam controladas por pessoas residentes ou domiciliadas no exterior. Reconheceu-se uma categoria mista, que é a empresa brasileira de capital predominantemente estrangeiro, sem chegar, todavia, à criação de um novo tipo de empresa.

Outra inovação afetando o critério tradicional relativo à nacionalidade das empresas surgiu a partir de 1969, através da legislação referente à aquisição de imóveis rurais por estrangeiros. Para esse efeito, serão tratadas como estrangeiras as pessoas jurídicas organizadas segundo a lei brasileira e tendo sede no Brasil, quando a maioria do capital social pertencer a pessoa física ou jurídica que resida ou tenha sede no exterior. Também aqui se deu o reconhecimento de uma situação mista, sem haver a criação de um novo tipo de sociedade. $O$ que importa assinalar é que o legislador brasileiro já percebeu que os critérios tradicionais, aplicáveis à definição de empresas como nacionais ou estrangeiras, não satisfazem, havendo necessidade de um reexame da matéria.

Procurando aperfeiçoar a disciplina do assunto, o anteprojeto de Código Civil, ora em debate, sugeriu várias inovações importantes, que afetarão a empresa multinacional, sobretudo nesse aspecto da nacionalidade. Assim, por exemplo, no artigo $2 .^{\circ}$ apareceu uma inovação muito séria, que é a permissão a que a lei estabeleça distinção entre nacionais e estrangeiros, quanto à aquisição e ao gozo de direitos privados. Se, na verdade, isso não é a criação do terceiro tipo, é, entretanto, a abertura de uma possibilidade de tratamento das empresas estrangeiras como estrangeiras, para efeitos de direito privado. $\mathrm{E}$, naturalmente, isso poderá e deverá alcançar as empresas multinacionais, se elas forem consideradas estrangeiras, por causa de sua origem. Mas já se alegou que aquela distinção entre nacionais e estrangeiros, para o gozo de direitos privados seria uma discriminação inconstitucional.

Um segundo ponto importante do anteprojeto é que o artigo 1316 define as sociedades nacionais procurando dar uma conceituação mais precisa do que sejam as "nacionais" para não permitir as "falsas nacionais" ou as "aparentemente nacionais". É ainda importante ressaltar o artigo 1324, segundo o qual toda empresa estrangeira que queira operar no Brasil ou 
funcionar no Brasil necessitará de uma autorização do governo brasileiro.

Trata-se, porém, apenas de um anteprojeto, são normas propostas à discussão, havendo ainda tempo para que se considere esse aspecto prévio fundamental que é a criação do tipo "empresa multinacional", o que será de muito mais eficiência e maior alcance do que a simples fixação de critérios mais precisos para conhecimento da nacionalidade das empresas.

\section{As Multinacionais e as Leis Nacionais}

Outro ponto também de grande importância é a verificação do comportamento das empresas multinacionais perante as leis nacionais. E aqui está precisamente um dos aspectos mais polêmicos, que é a discussão da possibilidade que tem a soberania de um Estado de exercer efetivo controle sobre a atuação da empresa multinacional. Será que realmente o Estado, que é soberano, tem essa possibilidade de controle?

O que a prática tem demonstrado é que as empresas multinacionais têm muitos meios para evitar a incidência de leis nacionais, para burlar a ação do poder soberano. Em relação a algumas áreas de atividades, como, por exemplo, quanto às matérias tributárias e trabalhistas, bem como quanto à matéria de política tributária e, em termos ainda mais concretos, relativamente à remessa de lucros para o exterior e à tributação de rendas, o que se sabe é que as empresas multinacionais têm relativa facilidade para burlarem a ação do poder soberano no Estado.

Entretanto, sentindo essa possibilidade de burla e conhecendo já, na prática, vários fatos dessa natureza, os Estados procuram reagir. E o que se verifica, quanto a essas reações, é que quando o conflito entre o comportamento de empresa multinacional e a soberania do Estado é um conflito patente - Estado procura impor sanções, de acordo com sua legislação específica. Isso parece fácil, mas o que normalmente ocorre é que as empresas multinacionais, sobretudo quando operam em Estados de menor nível de desenvolvimento, estão muito melhor aparelhadas para a defesa de seus interesses do que o próprio Estado. E então, tanto através de veículos legais, quanto através de meios extra-legais, a empresa multinacional cria obstáculos à ação soberana do Estado, ficando a soberania como um poder teoricamente superior mas praticamente ineficaz. 
Mas a ação do Estado, para defesa de seus interesses e preservação de sua soberania, encontra muito maior dificuldade quando há disfarce, ou seja, quando uma empresa, formalmente nacional mas componente de um grupo multinacional, oculta por muitos meios a verdadeira natureza de seus atos. Para que se tenha uma idéia dos meios utilizados para a burla e de seu alcance, basta lembrar que a empresa multinacional, entre outras coisas, tem a possibilidade de contratar consigo mesma. Tem, portanto, a possibilidade de simular contratos, tem a possibilidade de simular obrigações, tem a possibilidade de criar relações jurídicas que são apenas aparentes ou que ostentam uma natureza e se enquadram em espécies que não são exatamente aquelas que na realidade existem. $\tilde{\mathrm{E}}$ o caso, por exemplo, da simulação de uma dívida ou do uso desnecessário de uma patente para disfarçar uma remessa ilegal de lucros.

E para coibir essa burla disfarçada o Estado é obrigado a procurar caminhos indiretos, é forçado a desenvolver um grande esforço, antes de mais nada para provar a existência da burla. $\mathrm{O}$ caminho normalmente utilizado pelo Estado para atingir esse objetivo é a busca de uma configuração de fraude à lei, é a tentativa de demonstrar que a ação do componente do grupo multinacional foi fraudulenta.

Relativamente a essa caracterização da fraude à lei vem a propósito lembrar o que ensina IRINEU STRENGER, em sua obra Autonomia da Vontade em Direito Internacional Privado. Ensina o Professor STRENGER que a caracterização da fraude à lei, segundo o Direito Internacional Privado, exige a ocorrência de atos que comprovem a intenção de escapar à lei que, normalmente, seria aplicável a uma relação jurídica. Essa prova de intenção é o ponto crucial para que se chegue à caracterização da fraude. O que se verifica na prática é que a fraude é utilizada, às vezes, para fugir a qualquer incidência legal. Outras vezes se utiliza a fraude numa tentativa de fazer com que a subsidiária do grupo multinacional se coloque sob uma legislação mais favorável.

$\mathrm{E}$ através de toda essa movimentação, no quadro desse conflito, o que fica evidente é que a empresa multinacional tem enormemente facilitada sua ação fraudulenta, exatamente porque o Estado não dispõe de mecanismos adequados para fazer face ao comportamento das empresas multinacionais. O Estado deverá buscar a comprovação da fraude, deverá tentar fazer essa prova, tratando a empresa, que supôe fraudulenta, ou como empresa nacional ou como empresa estrangeira, valendo-se dos mecanismos normais que utiliza em relação às próprias empresas nacionais. 
Um problema correlato a esse que se acaba de mencionar é a questão da solução judicial dos conflitos envolvendo empresas multinacionais. Quanto a esse ponto o que fica patente é o agravamento da deficiência dos instrumentos jurídicos existentes.

$\mathrm{Na}$ realidade, já começa a ser bem difícil a solução do problema quando se verifica a inexistência de um tribunal específico para apreciar conflitos envolvendo empresas multinacionais. Essa lacuna, somada à inexistência de uma legislação específica sobre empresas multinacionais, que permita, inclusive, a adequada classificação jurídica da empresa como "multinacional", tudo isso acaba, inevitavelmente, criando uma série de dificuldades.

O que freqüentemente ocorre é que as empresas multinacionais, através dos contratos que celebram, sobretudo quando esses contratos envolvem dois membros do mesmo grupo multinacional, procuram afastar a competência dos Estados menos convenientes aos seus interesses. Mas se verifica também, em contrapartida, que cada Estado é cioso de sua própria competência, que é um atributo de sua soberania. E daí uma série de conflitos. O Estado querendo que a matéria fique no âmbito de sua competência e a empresa multinacional, por seu lado, querendo desviar a competência para um Estado que lhe seja mais favorável.

Também quanto a esses aspectos, é muito oportuno lembrar que o anteprojeto de Código Civil brasileiro, ora em debate, contém uma inovação importante em seu artigo 1327, que é a afirmação de que todas as sociedades estrangeiras ficam sujeitas às leis e aos tribunais brasileiros relativamente aos atos que produzam efeitos no Brasil. Talvez se pudesse dizer que isso é pouco mais do que aquilo que hoje já está contido na Lei de Introdução ao Código Civil, mas na verdade é bem mais, é uma extensão da possibilidade de assegurar a competência dos tribunais brasileiros. Entretanto, é ainda, uma solução precária, porquanto restará sempre o problema da inexistência de um tribunal especial, que tenha procedimentos especiais aplicáveis às empresas multinacionais.

$\mathrm{Na}$ prática, o que se verifica é que, em virtude dessa deficiência, raramente as empresas multinacionais têm seus problemas e seus conflitos discutidos num tribunal. A solução sempre buscada e sempre preferida, tanto nos conflitos com os poderes públicos, quanto nos conflitos com grupos privados, é a solução por via de negociação, ficando à margem o poder soberano do Estado. 


\section{As Multinacionais e os Interesses Nacionais}

Um outro aspecto, que de certa maneira complementa esse que acaba de ser exposto, é o comportamento das multinacionais perante os interesses nacionais. Não especificamente perante as leis nacionais, mas, mais propriamente, perante os interesses nacionais. E relativamente a esse aspecto e aos conflitos ligados a ele verifica-se a presença do fator emocional, mesmo na obra dos melhores autores, quando apreciam o problema.

Raymond Vernon vê um aspecto negativo para as multinacionais quando diz que elas estão sujeitas, ao mesmo tempo, a várias soberanias. No seu entender, esse é um dado que enfraquece as multinacionais e que fortalece a soberania dos Estados. Mas ele mesmo observa que, visto o problema do ponto de vista do Estado, o que se percebe é que os Estados sentem, no comportamento das multinacionais, a influência de decisões externas, oriundas do próprio grupo multinacional, de sua matriz ou de subsidiárias, e que vêm produzir efeitos dentro do âmbito do Estado. $\mathrm{E}$ às vezes, o que é ainda mais grave, através do comportamento de um componente de um grupo multinacional um Estado percebe e sofre a influência de decisões de outros Estados. Isso ocorre, por exemplo, quando certo Estado toma uma decisão que afeta substancialmente a atuação de um membro do grupo multinacional, ou de matriz ou de uma subsidiária, e por repercussão vai acabar atingindo os interesses ou a autoridade de um outro Estado.

Outro autor, o economista ROBERT HEILBRONER, defensor intransigente e entusiasta das multinacionais, aponta como um aspecto favorável aos Estados a circunstância de que as multinacionais são verdadeiros "reféns" nos Estados em que se instalam. Em que sentido isso ocorreria? Diz ele que as multinacionais são verdadeiros reféns porque muitas vezes, por causa de problemas e de conflitos políticos externos, até como atitude de vingança, os Estados procedem à nacionalização das empresas multinacionais.

Entretanto, é importante observar que, relativamente às nacionalizações, muita coisa se tem dito apontando decorrências positivas e negativas para os Estados. Alguns defensores das multinacionais consideram o Estado plenamente protegido, porque pode nacionalizar a seu exclusivo critério. Por outro lado, se tem ressaltado que essa possibilidade de nacionalização é, em boa medida e sob muitos aspectos, uma possibilidade negativa. Em primeiro lugar porque a nacionalização é uma providência excessivamente drástica. Muitas vezes é necessário ou 
conveniente ao Estado coibir apenas alguma prática, mas pela inexistência de instrumentos adequados, que possibilitem uma ação moderada, o Estado é obrigado à solução drástica, procedendo à nacionalização.

Além desse aspecto, que muitas vezes se tem revelado negativo, ou seja, além de ser excessivamente drástica, a nacionalização é quase sempre demasiadamente onerosa, sobretudo se considerarmos que a necessidade de nacionalizar ocorre com muito mais freqüência em Estados de nível relativamente baixo de desenvolvimento econômico.

Um terceiro aspecto também negativo, relacionado com a possibilidade de nacionalizar, é que a experiência tem revelado ser a nacionalização, normalmente, uma fonte de conflitos. Ainda que através dela alguns problemas possam ser resolvidos, sempre, inevitavelmente, do ato de nacionalização decorrem inúmeros conflitos. $\mathrm{E}$ estes muitas vezes são extremamente prejudiciais ao próprio Estado que procede à nacionalização. Por isso tudo se verifica que a nacionalização pode parecer o meio mais prático e mais eficiente para proteção da soberania dos Estados, em face das empresas multinacionais, mas é um meio precário, porquanto está eivado de inconvenientes.

\section{O Relacionamento das Multinacionais com a Soberania do Estado}

Vistos esses aspectos, já se pode concluir alguma coisa quanto ao relacionamento da soberania do Estado com as empresas multinacionais.

Não é esta, evidentemente, a oportunidade para o estudo aprofundado do problema, mas alguma coisa de original e positivo terá sido feito se obtivermos o seu equacionamento jurídico adequado.

Em primeiro lugar, verifica-se que a soberania, por seu próprio conceito, assegura a superioridade do Estado sobre qualquer outro poder no âmbito de seu território. Dessa maneira, também as empresas multinacionais ficam sempre submetidas ao poder soberano do Estado, colocando-se numa situação de dependência perante esse poder soberano.

A par disso, outra constatação importante é que, especialmente para os Estados mais carentes de recursos e que normalmente são mais procurados pelas multinacionais, é fundamental a preservação da soberania, uma vez que preci- 
samente esses Estados é que são os mais vulneráveis às investidas de outros centros de decisão. $\mathrm{E}$ é com base na soberania, isto é, porque dispõem de um poder soberano, que tais Estados, apesar de toda a precariedade de meios, têm alguma possibilidade de defesa contra essas investidas.

Uma terceira conclusão é que a indefinição jurídica quanto às empresas multinacionais cria embaraços à ação soberana dos Estados. Esse é, na verdade, um dos pontos mais relevantes, pois se percebe que é do interesse dos próprios Estados que se chegue a uma clara definição da situação jurídica das empresas multinacionais. Sem essa clara definição os Estados sempre terão enorme dificuldade para fazerem valer seu poder soberano. É, portanto, de seu interesse que haja instrumentos jurídicos adequados.

Deve-se observar também que essa definição jurídica, que é do interesse dos Estados, interessa igualmente às empresas multinacionais, que terão dessa maneira uma possibilidade de atuação mais definida, mais clara e menos arriscada. E para acentuar ainda mais a existência desse interesse recíproco, é também oportuno ressaltar que não é razoável, por não ter sentido prático, uma atitude "contra" a empresa multinacional ou "a favor" desse tipo de empresa. O que se deve ter em conta é que a empresa multinacional é um fenômeno, é um fato, de nossa época, sendo importante, isto sim, considerá-la e tratá-la adequadamente, procurando tirar dela e de sua atuação os benefícios e as vantagens que ela, inegavelmente, pode oferecer.

Por último, lembrando uma ponderação bastante feliz do Professor ALFREDO LAMY FILHo, o ideal seria a obtenção de uma legislação internacional uniforme, fixando as condições para a organização e o funcionamento das empresas multinacionais. Como elas operam num âmbito que excede o limite dos Estados, é indispensável que essa legislação proceda também de um âmbito situado além dos Estados. Esse é um ideal que já vem sendo buscado e para cuja consecução muitos obstáculos, alguns extremamente difíceis, terão que ser transpostos. Reconhecendo isso, diz ALFREDo LAMY FILHo que, enquanto não se atinge $o$ ideal da legislação internacional uniforme, cada Estado deve ir adaptando sua legislação, partindo do reconhecimento das empresas multinacionais como tais e buscando oferecer condições para a conciliação de interesses. Em lugar da mera atitude de combate ou da simples fixação de restrições, ou, ainda, da tentativa de fiscalização sem meios apropriados, deve-se procurar proceder ao enquadramento jurídico adequado das empresas multinacionais. 
Como conclusão final cabe assinalar que, respeitada a soberania dos Estados e com o auxílio do Direito, podem ser dadas condições para que as empresas multinacionais operem em qualquer Estado, proporcionando aos que as receberem os benefícios que elas podem oferecer, permitindo-se às empresas multinacionais que aufiram, como contraprestação, um proveito justo, correspondente a esses benefícios.

\section{Bibliografia Utilizada}

Bonavides, Paulo, Ciência Politica, Rio de Janeiro, Fundação Getúlio Vargas, 1967. Dallari, Dalmo A., Elementos de Teoria Geral do Estado, São Paulo, Saraiva, 7." ed., 1980 .

Hembroner, Robert L., As Empresas Multinacionais, In Diálogo, vol. V, n.` III, Rio de Janeiro, julho-agosto-setembro, 1972.

Kaplan, Morton A. e Katzenbach, Nicholas de B., Fundamentos Políticos do Direito Internacional, Rio de Janeiro, Zahar, 1964.

LAMY Filho, Alfredo, A Reforma da Lei de Sociedades Anônimas, in Revista de Direito Mercantil, Industrial, Econômico e Financeiro, n. ${ }^{\circ}$, São Paulo, Revista dos Tribunais, 1972.

ONU - Multinacional Corporation in World Development - Trabalho elaborado pelo Departamento de Assuntos Econômicos e Sociais do Secretariado das Nações Unidas - New York, 1973.

Reale, Miguel et alii, Anteprojeto de Código Civil, Departamento de Imprensa Nacional, 1972.

Strenger, Irineu, Da Autonomia da Vontade em Direito Internacional Privado, São Paulo, 1967.

VERNON, Raymond, Multinational Enterprise \& National Sovereignity, In Harward Business Review, vol. 45 março-abril, 1967.

- A Empresa Multinacional, in Diálogo, vol. III, n. ${ }^{\circ}$ I, Rio de Janeiro, abril-junho, 1969.

Tannenbaum, Frank, Além das Fronteiras da Nação-Estado, In Diálogo, vol. III, n. ${ }^{\circ}$ I, Rio de Janeiro, abril-junho, 1969. 